\title{
“O que é história, carta e notícia de jornal?" A definição de textos por crianças
}

\author{
Alina Galvão Spinillo ${ }^{\mathrm{a}}$, Ana Paula da Silva ${ }^{\mathrm{b}}$ (in memoriam) \\ aUniversidade Federal de Pernambuco, Recife, PE, Brasil, 'baculdade José Lacerda Filho de Ciências Aplicadas, Ipojuca, PE, Brasil
}

Resumo: $O$ desenvolvimento da linguagem escrita envolve diferentes conhecimentos sobre textos, incluindo a capacidade de pensar sobre suas propriedades (consciência metatextual). A presente investigação teve por objetivo investigar a consciência metatextual em crianças a partir da análise dos critérios que adotam ao definir história, carta e notícia de jornal. Quarenta crianças de baixa renda (7-9 anos), alunas do Ensino Fundamental responderam a seguinte pergunta: "O que é história/carta/notícia de jornal?". As definições foram classificadas em função dos critérios adotados (convenções linguísticas, estrutura, conteúdo, funções, características materiais do portador) e da forma como considerados (isoladamente ou combinados). As crianças de 7 anos apresentavam dificuldades em definir textos e adotavam os critérios isolados; enquanto as de 9 anos forneciam definições baseadas em critérios precisos e articulados. Os critérios adotados variavam também em função das características dos textos. Os dados contribuem para a compreensão do desenvolvimento do conhecimento metatextual.

Palavras-chave: conhecimento metatextual, definição de textos, crianças.

O conhecimento sobre algo pode ser investigado de diferentes maneiras. Em relação a pesquisas com crianças, é comum, por exemplo, solicitar a realização de atividades, a resolução de situações-problema, ou solicitar julgamentos (reconhecer ou identificar) acerca de aspectos relevantes do fenômeno investigado. No caso do desenvolvimento da linguagem escrita, no âmbito da psicologia cognitiva, este conhecimento tem sido investigado tanto em relação à palavra como em relação ao texto, fundamentalmente, a partir de situações envolvendo a escrita e a leitura. Entretanto, considerando o desenvolvimento da linguagem escrita ${ }^{2}$ no que concerne ao conhecimento sobre textos, recentemente, uma terceira via de investigação tem surgido, a qual se volta para a capacidade que os indivíduos possuem para realizar reflexões metalinguísticas sobre textos, reflexão esta denominada consciência metatextual (Gombert, 1992; Spinillo, 2009).

De acordo com Gombert (1992), pesquisador que cunhou este termo, a consciência metatextual se caracteriza como uma atividade realizada por um indivíduo que

1 As autoras agradecem às crianças que participaram deste estudo que permitiram que tivéssemos acesso às suas ideias sobre textos. Agradecimentos também são endereçados a Manuela Amorim que com sua sensibilidade acadêmica na escuta de crianças auxiliou na análise dos dados. Este trabalho é parte da dissertação de mestrado da segunda autora sob a orientação da primeira na Pós-Graduação em Psicologia Cognitiva da UFPE.

2 Pontecorvo (1997) faz a importante distinção entre escrita da linguagem e linguagem escrita. A escrita da linguagem trata os diferentes sistemas de escrita (natureza, aspectos notacionais, relações som-grafia etc.), enquanto a linguagem escrita focaliza o discurso, o texto e seus gêneros, abordagem esta que inclui a produção e a compreensão de textos escritos. Apesar de distintas, as duas abordagens são complementares tanto do ponto de vista psicológico como educacional.

* Autora correspondente: alinaspinillo@hotmail.com trata o texto como um objeto de análise, cujas propriedades podem ser examinadas a partir de um monitoramento intencional e deliberado, focalizando sua atenção no texto em si mesmo, e não em seus usos (compreensão e a produção).

Pesquisas que examinam o conhecimento a partir da produção (oral ou escrita) avaliam se os textos elaborados são coesos, coerentes e se apresentam uma estrutura e organização linguísticas apropriadas (Lins e Silva \& Spinillo, 1998; Pessoa, Correa, \& Spinillo, 2010; Rego, 1986; Shapiro \& Hudson, 1997; Spinillo, 1991, 1993, 2005; Spinillo \& Martins, 1997; Spinillo \& Oliveira e Silva, 2010; Spinillo \& Pinto, 1994). Spinillo (2001) menciona a diversidade de situações propostas pelos pesquisadores com o objetivo de levar a criança a produzir uma história: a partir de gravuras (isoladas, em sequência); de um filme, de um tema/título dado; a partir de material lúdico (brinquedos, fantoches); de outra história (lida ou ouvida); ou mesmo a partir de uma produção livre, sem que qualquer recurso visual ou verbal seja apresentado como estímulo.

Em outras pesquisas, o conhecimento sobre textos é avaliado a partir de situações em que a criança é solicitada a julgar se um texto apresentado está completo ou incompleto, ou a identificar o gênero do texto que está sendo apresentado (Albuquerque \& Spinillo, 1997, 1998; Barros \& Spinillo, 2011; Rego, 2005; Spinillo, 2009; Spinillo \& Pratt, 2005; Spinillo \& Simões, 2003; Stein \& Policastro, 1984).

Estudos como esses trazem informações relevantes acerca do conhecimento sobre textos. No entanto, esse conhecimento poderia ser examinado por outro método, há muito documentado na literatura: o método de definição. Utilizado por Luria (1990) ao investigar a formação de conceitos por parte de camponeses com níveis elementares de instrução, o método consiste em endereçar ao entrevistado 
a seguinte pergunta: “O que é X para você?". Definir algo, como afirma o autor, é uma operação verbal e lógica que envolve o manejo de uma série de ideias logicamente subordinadas para chegar a uma conclusão geral. Definir requer considerar atributos definidores e característicos dos objetos (Lomônaco, Caon, Heuri, Santos, \& Franco, 1996; Lomônaco, Paula, Mello, \& Almeida, 2001) que permitem inseri-lo em uma categoria genérica, entendendo-o como membro de uma classe e não como uma entidade isolada (Bruner, Goodnow, \& Austin, 1956/1967). Pelo que se apreende, portanto, a formação de conceitos é um processo mental que tem lugar de destaque no âmbito da psicologia cognitiva que, por sua natureza interdisciplinar, traz contribuições relevantes para a compreensão do desenvolvimento da linguagem como ilustrado neste estudo. No que tange à definição de conceitos, o ato de definir também se insere no âmbito da psicologia cognitiva por demandar, como mencionado, a realização de operações lógicas e de generalizações que se manifestam por meio de uma elaboração verbal que está ausente, por exemplo, no conhecimento que se manifesta por protótipos (ver Lomônaco et al., 1996, 2001).

Segundo Oliveira (1999), é relevante examinar a maneira como as crianças definem conceitos e quais os atributos que consideram. $\mathrm{O}$ método de definição tem sido utilizado em pesquisas acerca de conceitos diversos. Por exemplo, na área de aquisição de conceitos biológicos, Carey (1985) discute diversas pesquisas em que as crianças são solicitadas a definir o que é cérebro. Lautert e Spinillo (2002) examinaram o conceito de divisão em crianças, perguntando: "O que é dividir?". Tanto em um estudo como em outro, as diversas definições identificadas expressavam as noções das crianças a respeito destes conceitos, sendo possível examinar os aspectos considerados por elas como importantes e os equívocos a respeito de tais conceitos. Entretanto, pelo que se sabe, o método de definição ainda não foi adotado para investigar o conhecimento de crianças sobre textos; embora uma iniciativa nesta direção tenha sido feita por Spinillo e Pratt (2005) como discutido adiante.

Mas por que investigar o desenvolvimento da linguagem escrita no que concerne ao conhecimento sobre textos a partir do método de definição? Como mencionado anteriormente, é recente o interesse em examinar esse conhecimento a partir da consciência metatextual (Spinillo, 2009). Dentro desta perspectiva, o método de definição surge como um recurso metodológico não apenas inovador, mas também relevante para levar o indivíduo a refletir sobre as características e propriedades dos textos, sendo, portanto, interpretado como uma atividade de natureza metatextual. Não se deseja dizer com isto que o método de definição trata-se da única opção metodológica para investigar o conhecimento de crianças sobre as propriedades e características de textos (Albuquerque \& Spinillo, 1997, 1998), mas que este é um recurso que pode trazer informações relevantes a respeito deste conhecimento.

Assim, a presente pesquisa adota este método para examinar o conhecimento de crianças sobre textos comumente veiculados em uma sociedade letrada: história, carta e notícia de jornal. Antes de descrever o estudo propriamente dito, são apresentadas as características desses textos e discutidos os principais resultados de pesquisas na área.

\section{História, Carta e Notícia de Jornal: Suas Principais Características}

O conhecimento sobre textos é multifacetado: textos possuem uma materialidade linguística particular (convenções linguísticas, estrutura), tratam de conteúdos específicos e atendem a determinadas funções em uma sociedade (Hudson \& Shapiro, 1991; Tannen, 1982). Esses aspectos definem um determinado gênero de texto ${ }^{3}$ e o diferenciam de outros.

História, por exemplo, é um texto narrativo com uma estrutura típica amplamente investigada pelos estudiosos da Gramática de História (Brewer, 1985; Mandler \& Johnson, 1977; Rumelhart, 1975). Essa estrutura, conhecida como esquema de história, consiste em uma organização de componentes que, de forma breve, caracteriza-se por uma introdução da cena e dos personagens por meio de marcadores típicos de abertura ("Era uma vez...", "Foi um dia...”); pela descrição de eventos ordenados em cadeia e uma situação-problema (ou trama) que envolve metas a serem alcançadas e obstáculos a serem superados pelos protagonistas; e um final com o desfecho, geralmente expresso por marcadores típicos de fechamento ("... e foram felizes para sempre"), que contém a resolução da trama. O conteúdo trata de elementos de ficção, podendo também incluir temas relevantes como valores, crenças e conhecimentos que precisam ser preservados e transmitidos a gerações futuras. Além de seu caráter lúdico, a história pode ter a função de auxiliar na compreensão e resolução de conflitos pessoais e, ainda, ser utilizada no ensino dos vários temas do currículo escolar.

Carta, de acordo com Rego (1985) e Albuquerque e Spinillo (1998), apresenta uma sequência que se inicia pelo local e data e por uma saudação do remetente dirigida ao destinatário. Em seguida, são veiculadas informações de natureza pessoal (experiências, fatos e sentimentos); e o remetente endereça perguntas ao destinatário; sabendo, entretanto, que essas perguntas serão respondidas posteriormente, compreendendo que a carta se insere em um contexto de comunicação à distância e não de uma interação face a face. Ao final, tem-se a despedida, com manifestações afetivas e a identificação do remetente. O conteúdo é de caráter privado, sendo as informações verídicas e de interesse restrito aos interlocutores. A linguagem mais formal ou mais informal depende das relações entre o remetente e o destinatário, e dos objetivos da comunicação.

3 Gênero de texto é aqui considerado na perspectiva de van Dijk (1992, 1995, 1997) em que eventos comunicativos estão associados a uma estrutura esquemática (ou superestrutura) que caracteriza os gêneros textuais. 
Notícia de jornal, segundo Teberosky (1990, 1992, 1996), é de natureza informativa, versando sobre conteúdos relativos a acontecimentos reais e de interesse público. Coimbra (1983) e Sodré e Ferrari (1986) consideram que a notícia jornalística pode assumir características de três diferentes matrizes de gêneros ${ }^{4}$ : dissertativa, narrativa e descritiva. Embora sua estrutura não seja tão definida como a da história e a da carta, observa-se que a manchete sempre antecede a notícia propriamente dita; anunciando, de forma breve, o tópico central a ser tratado. Este, por sua vez, consiste na apresentação de seis itens básicos: o que, quem, quando, onde, como e por que (Lage, 1985). A ordem de aparecimento desses elementos é variável, dependendo da importância que possuem para um grupo social em um determinado momento, vindo primeiro o fato considerado mais relevante. Como norma de estilo, a linguagem deve evitar a primeira pessoa, a redundância, o emprego de palavras pouco frequentes e $o$ uso de termos vagos. Sua função principal é informar fatos de interesse para um determinado grupo social.

Pelo exposto, história, carta e notícia de jornal apresentam convenções linguísticas, estrutura e componentes próprios que os definem, e cumprem funções sociais distintas. Esses aspectos, de forma articulada, constituem os atributos que caracterizam esses textos. Seriam as crianças capazes de considerar tais atributos ao definir tais textos?

\section{História, Carta e Notícia de Jornal: Resultados de Pesquisas com Crianças}

Albuquerque e Spinillo $(1997,1998)$ investigaram o conhecimento de crianças sobre história, carta e notícia de jornal a partir de tarefas de produção e de identificação. No primeiro estudo (Albuquerque \& Spinillo, 1997), crianças de 5, 7 e 9 anos foram solicitadas a produzir oralmente uma história, uma carta e uma notícia de jornal (tarefa de produção) e a determinar se um texto-estímulo lido era uma história, uma carta ou uma notícia de jornal, justificando sua escolha (tarefa de identificação). As crianças de 5 anos apresentaram dificuldades na produção dos três textos; as de 7 anos tiveram dificuldades apenas em relação à carta; enquanto as de 9 anos apresentavam um domínio maior em relação aos três textos. Na tarefa de identificação, as crianças foram classificadas em níveis que se baseavam no número de acertos (identificação correta) e nas justificativas fornecidas (que variavam desde a ausência de critérios definidos até critérios precisos relativos às características linguísticas do texto, ao seu conteúdo e à sua função). Esses níveis expressam uma progressão quanto ao conhecimento sobre textos, de maneira que as crianças de 5 anos tendiam a se concentrar nos níveis mais elementares; enquanto as de 7 e 9 anos no nível mais elaborado.

4 De acordo com Guimarães (2001) e van Dijk (1992, 1995, 1997), essa tipologia deriva de uma análise voltada para a estrutura interna dos textos denominada superestrutura, que é um esquema que estabelece a organização e constituição global do texto. Embora possua uma estrutura dominante, o texto pode apresentar uma combinação de outros textos, assumindo uma estrutura mista em que mais de uma matriz está presente.
Os resultados mostraram, ainda, que os critérios adotados variavam em função do texto: o conteúdo era mais adotado na identificação da notícia do que na identificação da história; enquanto as convenções linguísticas ("Era uma vez...") eram mais adotadas na identificação da história do que da carta. Comparações entre produção e identificação não se correlacionaram sistematicamente, variando de acordo com o tipo de texto, não havendo uma progressão geral que pudesse englobar essas duas habilidades.

Dado que na tarefa de identificação no primeiro estudo as crianças não adotavam a estrutura como critério, as autoras realizaram uma segunda investigação (Albuquerque \& Spinillo, 1998), em que a criança era solicitada a dizer se um texto lido (histórias, cartas e notícias de jornal) estava completo ou incompleto, justificando sua resposta. Diferentes níveis de respostas foram identificados, observando-se o uso da estrutura como critério para julgar a completude e incompletude dos textos. As crianças mais velhas ( 9 anos), inclusive, eram capazes de determinar, nos textos incompletos, a parte que estava ausente.

Considerando esses resultados de forma conjunta, nota-se que as crianças de 5 anos adotam o conteúdo e o tamanho do texto em seus julgamentos, enquanto crianças mais velhas consideram os aspectos linguísticos e estruturais do texto. Observou-se ainda que a habilidade de refletir sobre a estrutura depende não apenas da idade e da escolaridade, mas também das características do texto, visto que a estrutura é mais saliente em alguns textos (como a história) do que em outros (notícia de jornal). Uma ampla discussão acerca dos principais resultados de pesquisa nesta área foi realizada por Spinillo (2009), que apresenta também uma proposta de um modelo de desenvolvimento da consciência metatextual.

Spinillo e Pratt (2005) aplicaram as tarefas de Albuquerque e Spinillo (1997) em crianças de classe média (7-8 anos), alunas do $2^{\circ}$ ano do Ensino Fundamental, e em crianças moradoras de rua de baixa renda (9-10 anos), com pouca ou nenhuma escolaridade. Com alguns dos participantes foi realizada uma entrevista com vistas a conhecer as experiências que tinham com histórias, cartas e notícias de jornal em casa, na rua e na escola; solicitando-se, ainda, que definissem história, carta e notícia de jornal. As crianças de classe média apresentavam um maior conhecimento sobre histórias e cartas do que as crianças de rua. Essas últimas, por outro lado, apresentavam desempenho semelhante ou mesmo superior ao das crianças de classe média em relação à notícia de jornal. Esses resultados foram explicados em termos do contato e experiência (formal e informal) que essas crianças possuem com esses textos no cotidiano, visto que para as crianças de rua notícias de jornal são mais familiares do que cartas e histórias.

Nesta investigação, as definições das crianças eram em número bastante reduzido e foram analisadas de maneira superficial, visto não serem o foco principal daquele estudo. Portanto, parece ser necessário explorar esta questão de forma mais sistematizada, como feito na presente pesquisa. Perguntar "O que é uma história/ uma carta/ uma 
notícia de jornal/?" pode suscitar respostas que expressem as concepções que a criança apresenta sobre esses textos. Para uma criança, quais seriam, por exemplo, os atributos definidores de história, de carta ou de uma notícia de jornal? Seriam atributos relativos às propriedades estruturais e linguísticas do texto? Seriam atributos de outra ordem, como seus usos e funções ou seu conteúdo? Assim, a presente pesquisa tem por objetivo examinar o conhecimento de crianças sobre textos a partir dos critérios que adotam ao definir história, carta e notícia de jornal. Quais seriam esses critérios? Seriam eles considerados isoladamente ou de forma articulada? O uso desses critérios variaria em função das características do texto? Ou variaria apenas em função da idade/escolaridade?

\section{Método}

\section{Participantes}

Quarenta crianças de ambos os sexos, de baixa renda, entre 7 e 9 anos de idade, alunas de escolas públicas na cidade de Paulista, Pernambuco, foram igualmente divididas em dois grupos em função da escolaridade: $2^{\circ}$ e $4^{\circ}$ ano do Ensino Fundamental. A escolha desta faixa etária e escolaridade deveu-se ao fato de que é por volta deste período que emergem conhecimentos de natureza metatextual. A participação das crianças foi autorizada pelos pais/responsáveis, após esclarecimentos sobre a pesquisa, de acordo com os termos do Comitê de Ética em Pesquisa da Universidade Federal de Pernambuco (Protocolo de Pesquisa 077/2004).

\section{Procedimento}

Cada criança foi entrevistada em uma única sessão, em que a pergunta-chave era: "Para você, o que é uma história/carta/notícia de jornal?". Outras perguntas foram feitas com vistas a esclarecer e aprofundar a resposta dada. A ordem do texto referido na pergunta-chave (história, carta ou notícia de jornal) foi decidida por sorteio com cada participante. A entrevista foi registrada em áudio e transcrita para análise.

\section{Análise dos Dados}

A partir das respostas, foram identificados os critérios que as crianças adotavam em suas definições (Tabela 1), a saber: Critério 1 - vago ou subjetivo; Critério 2 - aspectos materiais do portador do texto $)$; Critério 3 - usos e funções; Critério 4 - conteúdo e personagens; e Critério 5 - estrutura e convenções linguísticas (ausente na definição de notícia de jornal). Alguns critérios se referiam a aspectos

5 Ver Moreira (1992) para maiores detalhes acerca desse termo. Um livro, por exemplo, pode ser o portador de diferentes textos, como histórias, poesias, receitas culinárias, exercícios escolares etc.; um jornal pode ser o portador de notícias jornalísticas, poesias, receitas culinárias etc. extratextuais como os aspectos materiais do portador (aspectos gráficos) e os usos e as funções que o texto cumpre em uma sociedade; enquanto outros se referiam a aspectos intratextuais, como o conteúdo, a estrutura e as convenções linguísticas que caracterizam os textos investigados.

Em algumas definições, apenas um desses critérios era mencionado de forma isolada, enquanto que, em outras, diversos critérios eram adotados de forma combinada. Considerando tais aspectos, as definições foram agrupadas em três tipos:

Definição 1: não define ou definição com critérios vagos e subjetivos (Critério 1).

Definição 2: definições em que apenas os aspectos extratextuais são considerados, como os aspectos gráficos do portador (Critério 2) e os usos e as funções do texto em uma sociedade (Critério 3). Estes critérios eram mencionados de forma isolada.

Definição 3: definições que se caracterizam pela combinação de critérios intra e extratextuais. Assim, havia definições em que os critérios eram intratextuais (estrutura e conteúdo, estrutura e convenções linguísticas, conteúdo e convenções linguísticas); e definições em que um dos critérios era intratextual e os demais extratextuais (estrutura e função, função e conteúdo, conteúdo e estrutura). Exemplos:

Exemplo 1: O que é uma história para você? "É, por exemplo, eu tô contando da vida da pessoa que aconteceu, ou uma fábula, ou senão uma história que eu tô inventando. Tem que ter começo, meio e fim" (conteúdo e estrutura).

Exemplo 2: Você sabe o que é uma carta? Diz para mim o que é uma carta.

"É quando uma pessoa tá longe e manda uma carta quando não pode ir na casa que é muito longe. Quando tá avisando que não pode ir visitar porque o filho tá doente" (função e conteúdo).

Exemplo 3: O que é notícia de jornal para você?

"Tem coisas graves e tem coisas de esporte. Como se fosse o noticiário, um meio de comunicação. Tem que ter coisas que acontecem" (conteúdo e função)

Exemplo 4: O que é uma história para você?

"É um texto que fala assim, 'Era uma vez., no começo. E depois termina, tem o final com "... e aí foram felizes para sempre"' (convenções linguísticas e estrutura)

Exemplo 5: O que é uma carta?

"É como se eu tivesse falando o que tá acontecendo comigo. Ai pego e fico contando e no final eu digo: 'Estou com saudades, volte logo"' (conteúdo e estrutura) 
Tabela 1

Exemplos dos critérios adotados na definição de história, carta e notícia de jornal

\begin{tabular}{|c|c|c|c|}
\hline Critérios & História & Carta & Notícia de jornal \\
\hline $\begin{array}{c}\mathrm{Cl} \\
\text { (vago e subjetivo) }\end{array}$ & $\begin{array}{c}\text { Acho engraçada e muito boa de } \\
\text { ouvir. }\end{array}$ & $\begin{array}{l}\text { É uma coisa que dá alegria pra } \\
\text { gente. }\end{array}$ & É boa pra ler. \\
\hline $\begin{array}{c}\mathrm{C} 2 \\
\text { (aspectos materiais) }\end{array}$ & $\begin{array}{c}\text { Tem os desenhos, os nomes e um } \\
\text { livrinho. }\end{array}$ & $\begin{array}{l}\text { Eu acho que é um papel que os } \\
\text { outros escrevem e pegam um } \\
\text { envelope e colocam dentro. }\end{array}$ & $\begin{array}{c}\text { Tem que ter fotos e letrinhas pra } \\
\text { pessoa ficar lendo. }\end{array}$ \\
\hline \multirow[t]{2}{*}{$\begin{array}{c}\text { C3 } \\
\text { (usos e funções) }\end{array}$} & \multirow{2}{*}{$\begin{array}{l}\text { Tem que ter uma coisa que a } \\
\text { criança possa aprender. }\end{array}$} & $\begin{array}{c}\text { É pra dar pra os outros pra abrir } \\
\text { e ler. }\end{array}$ & $\begin{array}{l}\text { É que diz coisa pro povo todo, } \\
\text { que quer saber. }\end{array}$ \\
\hline & & Saber do recado da pessoa. & $\begin{array}{l}\text { A pessoa lê pra saber das } \\
\text { coisas. }\end{array}$ \\
\hline $\begin{array}{c}\mathrm{C} 4 \\
\text { (conteúdo, personagens) }\end{array}$ & $\begin{array}{l}\text { Um bocado de bruxa, fantasma, } \\
\text { menina e menino. }\end{array}$ & $\begin{array}{c}\text { É como se eu tivesse falando o que } \\
\text { está acontecendo comigo. }\end{array}$ & É do que aconteceu nas ruas. \\
\hline \multirow{2}{*}{$\begin{array}{l}\text { C5 } \\
\text { (estrutura e convenções } \\
\text { linguísticas) }\end{array}$} & $\begin{array}{c}\text { É quando começa com "Era uma } \\
\text { vez..." }\end{array}$ & $\begin{array}{c}\text { Aí pego e fico contando e no final } \\
\text { eu digo: "Estou com saudades, } \\
\text { volte logo." }\end{array}$ & \\
\hline & Tem que ter começo, meio e fim. & & \\
\hline
\end{tabular}

\section{Resultados}

Das 120 definições apresentadas, apenas $13(10,8 \%)$ eram Definição 1, enquanto $52(43,4 \%)$ eram Definição 2 e $55(45,8 \%)$ eram Definição 3. Esses percentuais indicam que as crianças tendem a oferecer definições baseadas em critérios precisos sejam eles intra ou extratextuais.

O Teste de Wilcoxon não detectou diferenças significativas em qualquer um dos três tipos de definição que pudessem ser atribuídas ao texto que estava sendo definido. Isso mostra que a definição dada não varia em função de o texto ser uma história, uma carta ou uma notícia de jornal, como pode ser visto na Tabela 2.

Tabela 2

Número e porcentagem (entre parênteses) de definições em cada texto

\begin{tabular}{lccc}
\hline & HISTÓRIA & CARTA & $\begin{array}{c}\text { NOTÍCIA } \\
\text { DE } \\
\text { JORNAL }\end{array}$ \\
\hline Definição $1(\mathrm{n}=13)$ & $4(31)$ & $5(38)$ & $4(31)$ \\
\hline Definição $2(\mathrm{n}=52)$ & $16(30,8)$ & $18(34,6)$ & $18(34,6)$ \\
\hline Definição $3(\mathrm{n}=55)$ & $20(36,4)$ & $17(30,9)$ & $18(32,7)$ \\
\hline $\begin{array}{l}\text { Nota: } \text { D1 - não define ou fornece definições vagas, subjetivas; D2 - aspectos } \\
\text { extratextuais considerados isoladamente; e D3 - aspetos intra e extratex- } \\
\text { tuais considerados de forma combinada. }\end{array}$
\end{tabular}

Para examinar se as definições variavam em função dos anos escolares (Tabela 3), aplicou-se o Teste U de
Mann-Whitney. Diferenças significativas foram encontradas apenas em relação à Definição $1(\mathrm{U}=100, \mathrm{p}=0,00)$, que era dada pelas crianças do $2^{\circ}$ ano.

Tabela 3

Número e porcentagem (entre parênteses) de definições em cada ano escolar

\begin{tabular}{lcc}
\hline & $\mathbf{2}^{\mathbf{0}}$ ANO & $\mathbf{4}^{\mathbf{0}}$ ANO \\
\hline Definição $1(\mathrm{n}=13)$ & $13(100)$ & 0 \\
\hline Definição 2 $(\mathrm{n}=52)$ & $26(50)$ & $26(50)$ \\
\hline Definição 3 $(\mathrm{n}=55)$ & $21(38,2)$ & $34(61,8)$ \\
\hline
\end{tabular}

Nota: D1 - não define ou fornece definições vagas, subjetivas; D2 - aspectos extratextuais considerados isoladamente; e D3 - aspetos intra e extratextuais considerados de forma combinada.

De acordo com o Qui-quadrado para amostra úni$\mathrm{ca}$, apenas entre as crianças do $4^{\circ}$ ano havia diferenças significativas entre as definições $(X=5,3 ; g l=2 ; p=0,008)$ devido ao fato de a Definição 1 estar ausente neste nível de escolaridade.

A Tabela 4 ilustra a distribuição das definições em cada ano escolar e em cada tipo de texto.

No que concerne à história, a Definição 1 estava presente apenas entre as crianças do $2^{\circ}$ ano e a Definição 3 era mais adotada pelas do $4^{\circ}$ ano (T-Teste, $\mathrm{p}<0,05$ ). $\mathrm{O}$ Qui-quadrado para amostra única revelou que as definições variavam apenas entre as crianças do $4^{\circ}$ ano $(X=5,5$; $\mathrm{gl}=2 ; \mathrm{p}=0,008)$, pois a Definição 3 era a mais adotada e a Definição 1 estava ausente. 
Em relação à carta, diferenças entre os anos escolares ocorreram exclusivamente em relação à Definição 1 (T-Teste: $p=0,016$ ) que era dada apenas pelas crianças do $2^{\circ}$ ano. O Qui-Quadrado para amostra única detectou diferenças significativas entre as definições apenas em relação às crianças do $4^{\circ}$ ano $(X=5,2 ; \mathrm{gl}=2 ; \mathrm{p}=0,007)$ devido ao fato de que a Definição 1 estava ausente.

Quanto à notícia de jornal, variações entre os anos escolares ocorreram apenas em relação à Definição 1 (T-Test: $p=0,036)$, presente apenas entre as crianças do $2^{\circ}$ ano. O Qui-Quadrado para amostra única revelou diferenças entre as definições tanto em relação ao $2^{\circ}$ ano $(\mathrm{X}=12,1 ; \mathrm{gl}=2 ; \mathrm{p}=0,002)$ como em relação ao $4^{\circ}$ ano $(\mathrm{X}=13,2 ; \mathrm{gl}=2 ; \mathrm{p}=0,002)$ : no $2^{\circ}$ ano, a Definição 2 era mais frequente e no $4^{\circ}$ ano era a Definição 3.

\section{Tabela 4}

Número e porcentagem (entre parênteses) de definições relativas à história, à carta e à notícia de jornal em cada ano escolar

\begin{tabular}{ccc}
\hline & História \\
& $\mathbf{2}^{\mathbf{0}}$ ANO & $\mathbf{4}^{\mathbf{0}}$ ANO \\
\hline D 1 (n=4) & $4(100)$ & 0 \\
\hline D2 (n=16) & $9(56,3)$ & $7(43,7)$ \\
\hline D3 (n=20) & $7(35)$ & $13(65)$ \\
\hline \multicolumn{3}{c}{ Carta } \\
\hline D1 (n=5) & $5(100)$ & 0 \\
\hline D2 (n=18) & $8(44,4)$ & $10(55,6)$ \\
\hline D3 (n=17) & $7(41,2)$ & $10(58,8)$ \\
\hline \multicolumn{3}{c}{ Notícia de Jornal } \\
\hline D1 (n=4) & $4(100)$ & 0 \\
\hline D2 (n=3) & $2(66,7)$ & $1(33,3)$ \\
\hline D3 (n=33) & $14(42,4)$ & $19(57,6)$ \\
\hline
\end{tabular}

Nota: D1 - não define ou fornece definições vagas, subjetivas; D2 - aspectos extratextuais considerados isoladamente; e D3 - aspetos intra e extratextuais considerados de forma combinada.

\section{Discussão e Conclusões}

O primeiro ponto que merece ser mencionado nesta seção final do artigo refere-se às relações entre conhecimento sobre textos e desenvolvimento da linguagem escrita. Este desenvolvimento inclui compreender a linguagem escrita tanto no âmbito da palavra como do texto, alargando, assim, a natureza da reflexão que se pode fazer sobre as diferentes facetas envolvidas neste desenvolvimento. Três grandes grupos de pesquisas podem ser identificados na literatura na área: (i) estudos que investigam a produção escrita, seja em termos notacionais, seja em termos de produção de textos; (ii) estudos que investigam a leitura, voltando-se para aspectos que variam desde a habilidade de decodificação e reconhecimento de palavras até a compreensão de textos por parte do leitor; e (iii) estudos que investigam o conhecimento que os indivíduos, sobretudo leitores iniciantes, possuem sobre textos que circulam na modalidade escrita em uma sociedade. Este último enfoque é recente e tem contribuído com novas informações e novas perspectivas a respeito da aquisição da escrita e seu desenvolvimento, sendo este o enfoque adotado na presente investigação.

O conhecimento de crianças sobre textos, a partir do método de definição, foi examinado com base nos critérios que adotam ao definir história, carta e notícia de jornal. Esses critérios estão claramente associados às características dos textos investigados, a saber: suas convenções linguísticas, sua estrutura, o conteúdo neles tratados e as funções que cumprem em uma sociedade. Além desses, as definições também versavam sobre critérios associados à materialidade do portador que veicula o texto. Este é um dado novo frente à literatura, uma vez que em pesquisas anteriores (Albuquerque \& Spinillo, 1997; 1998) os critérios adotados por crianças de faixa etária semelhante para identificar esses mesmos textos não incluíam critérios desta natureza. Uma explicação para isso é que ao definir, diferentemente do que ocorre ao emitir julgamentos como ocorridos naquelas pesquisas, as crianças parecem ampliar o conjunto de critérios que adotam, passando a incluir o portador de texto. De fato, definir é uma medida de generalidade que remete a um sistema de relações, de maneira que um caso específico (um texto lido, por exemplo) faz parte de uma categoria mais ampla (o texto lido é uma história, por exemplo). Isso implica a ideia de uma hierarquia de classes e sub-classes, ideia esta fundamental na formação de conceitos (Luria, 1990; Vygotsky, 1991). Importante comentar que o estudo de Rego (2005), que também investigava as concepções sobre textos (no caso, a história exclusivamente), por não utilizar o método de definição, não capturou a emergência de determinados critérios que surgiram em decorrência do método de definição.

Corroborando os dados obtidos por Albuquerque e Spinillo (1997, 1998), os critérios estão associados às características do texto. Por exemplo, a estrutura e as convenções linguísticas não eram mencionadas ao definir a notícia, sendo o conteúdo o único aspecto intratextual considerado em sua definição. Isso se explica porque a notícia, como discutido, não possui uma estrutura fixa e, além disso, assume características de diferentes matrizes de gêneros (dissertativa, narrativa e descritiva). Este fato fez que a estrutura fosse considerada um aspecto pouco definidor da notícia.

O fato de os critérios na presente pesquisa serem muito semelhantes àqueles identificados em estudos anteriores realizados com outros métodos de investigação (Spinillo, 2009), indica que esses critérios apresentam certa estabilidade, sendo características que a criança adota tanto em situações de produção e de julgamento de textos como em 
situações em que é solicitada a fornecer uma definição. O método de definição parece, portanto, outra possibilidade de investigação acerca do conhecimento sobre textos que, por sua vez, é uma manifestação do desenvolvimento na aquisição da escrita enquanto sistema de comunicação e registro.

Importante comentar que os dados obtidos sugerem uma progressão a respeito do conhecimento sobre textos. Isso é ilustrado pela Definição 3 que tanto expressa a capacidade da criança de articular diferentes critérios em uma mesma definição como também a capacidade de considerar os aspectos internos ao texto como sua estrutura e convenções linguísticas. Tais definições parecem indicar, ainda que de forma elementar, o esboço de uma atividade metatextual em que a criança toma o texto como objeto de reflexão e análise (Gombert, 1992). Esta progressão está associada à escolaridade, uma vez que as crianças do $2^{\circ}$ ano apresentavam alguma dificuldade em definir textos, enquanto as crianças do $4^{\circ}$ ano sempre forneciam definições baseadas em critérios precisos, fossem eles intra ou extratextuais. Esta progressão, em última instância, está associada ao desenvolvimento das concepções que leitores e escritores iniciantes apresentam a respeito da linguagem escrita que se materializa em textos que precisam ser produzidos, compreendidos e analisados quanto às suas características e propriedades.
Inserindo esta discussão em um cenário mais amplo, cabe comentar que a progressão identificada a respeito do conhecimento sobre textos está associada também a um conhecimento metalinguístico que pode ser desenvolvido no contexto escolar a partir de aprendizagens explícitas (Maluf, 2010; Paula, Correa, \& Spinillo, 2012).

Para finalizar, seria interessante examinar o conhecimento sobre textos a partir de situações distintas de investigação; comparando, por exemplo, o mesmo grupo de crianças ao julgar e definir diferentes gêneros textuais. Essas mesmas habilidades metatextuais poderiam ser comparadas com a habilidade de produção textual nos mesmos participantes.

Em termos de implicações educacionais que possam promover o conhecimento acerca da linguagem escrita, é possível pensar-se em situações didáticas que levem o aluno a expressar suas concepções sobre textos (definir, por exemplo) e a refletir sobre as características e propriedades de textos de diferentes gêneros. Seja por meio da definição, seja por outras situações, fazer do texto um objeto de reflexão e análise é fundamental para o desenvolvimento da linguagem escrita, tendo a escola papel fundamental neste desenvolvimento.

\title{
What is a story, a letter and a news article?" Text definition by children
}

\begin{abstract}
Knowledge about texts was examined using the definition method, investigating the criteria children use to define story, letter, and newspaper article. Forty working-class children (7-9 years old) attending the 2nd and the 4th grade of elementary school were asked the following question: "What is a story/letter/newspaper article?"The definitions were classified according to the criteria adopted (linguistic conventions, structure, content, functions, material aspects) and the way the criteria were considered (in isolation or in combination). The $2^{\text {nd }}$ graders showed some difficulty in defining texts and used the criteria in isolation. The 4th graders, however, gave definitions based on precise criteria, used in combination. The criteria also varied according to the properties of the texts. The findings contributed to the understanding of the development of metatextual knowledge in children.
\end{abstract}

Keywords: metatextual knowledge, text definition, children.

\section{Qu'est-ce que I'histoire, la lettre et l'article de jornal ? » La définition des textes pour les enfants}

Résumé: Le développement du langage écrit comporte des différentes connaissances sur les textes, cela inclut la capacité de penser sur ses propriétés (conscience métatextuelle). La présente investigation a eu pour objectif d'explorer la conscience métatextuelle des enfants a partir de l'analyse des critères qu'ils adoptent pour définir l'histoire, la lettre et l'article de journal. Quarante enfants, élèves de primaire (7-9 ans), issu d'une classe sociale basse, ont répondu à la question suivante : "Qu'est-ce que l'histoire/ la lettre/l'article de journal? ». Les définitions ont été classées en fonction des critères utilisés (conventions linguistiques, structures, contenus, fonctions, caractéristiques matérielles du porteur) et de la façon dont ils sont considérés (isolés ou combinés). Les enfants de 7 ans présentaient des difficultés à définir les textes et utilisaient les critères isolés; alors que les enfants de 9 ans donnaient des définitions basées sur des critères précis et articulés. Les critères utilisés ont également varié en fonction des caractéristiques des textes. Les données ont contribué à la compréhension du développement de la connaissance métatextuelle.

Mots clés: connaissance métatextuelle, définition des textes, enfants. 


\section{¿Qué es historia, carta y noticia de periódico?" La definición de textos por niños}

Resumen: El conocimiento sobre textos fue examinado a través del método de definición en relación a diferentes tipos de textos, investigándose los criterios que los niños adoptan al definir historia, carta y noticia de periódico. A cuarenta niños de baja

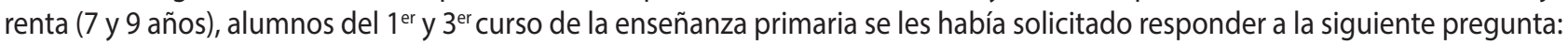
"¿Qué es historia/carta/ noticia de periódico?". Las definiciones habían sido clasificadas por criterios adoptados (convenciones lingüísticas, estructura, contenido, funciones, aspectos gráficos y portador) y por forma (aisladamente o combinados). Los niños del $1^{\text {er }}$ curso presentaban cierta dificultad en definir textos y adoptaban los criterios de forma aislada; mientras que los niños del $3^{\text {er }}$ curso suministraban definiciones basadas en criterios precisos y de forma combinada. Los criterios variaban en función del tipo de texto, habiendo aquellos que eran más asociados a un tipo de texto que a otros.

Palabras clave: conocimiento sobre textos, definición de textos, tipos de textos, niños.

\section{Referências}

Albuquerque, E. B. C., \& Spinillo, A. G. (1997). O conhecimento de crianças sobre diferentes tipos de textos. Psicologia: Teoria e Pesquisa, 13(3), 329-338.

Albuquerque, E. B. C., \& Spinillo, A. G. (1998). Consciência textual em crianças: critérios adotados na identificação de partes de textos. Revista de Estúdios e Investigación en Educación, 3(2), 145-158.

Barros, M. T. A., \& Spinillo, A. G. (2011). Contribuições da educação infantil para o letramento: um estudo a partir do conhecimento de crianças sobre textos. Psicologia: Reflexão e Crítica, 24(3), 542-550.

Brewer, C. (1985). The story schema: Universal and culturespecific properties. In D. R. Olson, N. Torrance \& A. Hildyard (Eds.), Literacy, language and learning: The nature and consequences of reading and writing (pp. 167-194). Cambridge: Cambridge University Press.

Bruner, J. S., Goodnow, J. J., \& Austin, G. A. (1967). A study of thinking. New York: Wiley. (Trabalho riginal publicado em 1956)

Carey, S. (1985). Conceptual change in childhood. Massachusetts: MIT Press.

Coimbra, O. (1993). O texto da reportagem impressa: um curso sobre sua estrutura. São Paulo: Ática.

Gombert, J. E. (1992). Metalinguistic development. Harvester: Wheatsheaf.

Guimarães, E. (2001). A articulação do texto. São Paulo, SP: Editora Ática.

Hudson, J. A., \& Shapiro, L. R. (1991). From knowing to telling: The development of children's scripts, stories, and personal narratives. In A. McCabe \& C. Peterson (Eds.), Developing narrative structure (pp. 89-136). Hillsdale, NJ: Lawrence Erlbaum Associates.

Lage, N. (1985). Estrutura da notícia. São Paulo: Ática.

Lautert, S. L., \& Spinillo, A. G. (2002). As relações entre o desempenho em problemas de divisão e as concepções de crianças sobre a divisão. Psicologia: Teoria e Pesquisa, 18(3), 237-246.

Lins e Silva, M. E., \& Spinillo, A. G. (1998). Uma análise comparativa da escrita de histórias por alunos de escolas públicas e particulares. Revista Brasileira de Estudos Pedagógicos, 79(193), 5-16.
Lins e Silva, M. E., \& Spinillo, A. G. (2000). A influência de diferentes situações de produção na escrita de histórias. Psicologia: Reflexão e Crítica, 13(3), 337350 .

Lomônaco, J. F. B., Caon, C. M., Heuri, A. L. P. V., Santos, D. M. M., \& Franco, G. T. (1996). Do característico ao definidor: um estudo exploratório sobre o desenvolvimento de conceitos. Psicologia: Teoria $e$ Pesquisa, 12(1), 51-60.

Lomônaco, J. F. B., Paula, F. V., Mello, C. B., \& Almeida, F. A. (2001). Desenvolvimento de conceitos: o paradigma das transformações. Psicologia: Teoria e Pesquisa, $17(2), 161-168$.

Luria, A. R. (1990). Desenvolvimento cognitivo. São Paulo, SP: Ícone.

Maluf, M. R. (2010). Do conhecimento implícito à consciência metalinguística indispensável na alfabetização. In S. R. K. Guimarães \& M. R. Maluf (Orgs.), Aprendizagem da linguagem escrita: contribuições da pesquisa (pp. 1732). São Paulo, SP: Vetor.

Mandler, J. M., \& Johnson, N. S. (1977). Remembrance of things parsed: Story structure and recall. Cognitive Psychology, 9, 1151.

Moreira, N. C. R. (1992). Portadores de texto: concepções de crianças quanto a atributos, funções e conteúdo. In M. A. Kato (Org.), A concepção da escrita pela criança (pp. 15-52). Campinas, SP: Pontes.

Oliveira, M. K. (1999). Três questões sobre desenvolvimento conceitual. In M. B. Oliveira \& M. K. Oliveira (Orgs.), Investigações cognitivas: conceitos, linguagem e cultura (pp. 55-64). Porto Alegre, RS: Artmed.

Paula, F. V., Correa, J., \& Spinillo, A. G. (2012). O conhecimento metalinguístico de crianças: o papel das aprendizagens implícitas e explícitas. In M. A. L. Dias, K. O. Fukumitsu \& A. F. T. de Melo (Orgs.), Temas contemporâneos em Psicologia do Desenvolvimento (pp. 161-196). São Paulo, SP: Vetor.

Pessoa, A. P. P., Correa, J., \& Spinillo, A. G. (2010). Contexto de produção e o estabelecimento da coerência na escrita de histórias por crianças. Psicologia: Reflexão e Crítica, 23(2), 253-260. 
Pontecorvo, C. (1997). Studying writing and writing acquisition today: A multidisciplinary view. In C. Pontecorvo (Org.), Writing development: An interdisciplinary view (pp. Xvxxxi). Philadelphia: John Benjamins.

Rego, L. L. B. (1985). Descobrindo a língua escrita antes de aprender a ler: algumas implicações pedagógicas. Revista Brasileira de Estudos Pedagógicos, 66, 5-27.

Rego, L. L. B. (1986). A escrita de estórias por crianças: as implicações pedagógicas do uso de um registro linguístico. Revista de Documentação de Estudos em Linguística Teórica e Aplicada, 2, 165-180.

Rego, L. L. B. (2005). Um estudo exploratório dos critérios utilizados pelas crianças para definir histórias. In M. G. B. B. Dias \& A. G. Spinillo (Orgs.), Tópicos em Psicologia Cognitiva (2a ed., pp. 120-138). Recife: Editora Universitária da UFPE.

Rumelhart, D. (1975). Notes on a schema for stories. In D. G. Bobrow \& A. Collins (Eds.), Representation and understanding: Studies in cognitive science (pp. 211236). New York, NY: Academic Press.

Shapiro, R. L., \& Hudson, J. A. (1997). Coherence and cohesion in children's stories. In J. Costermans \& M. Fayol (Eds.), Processing interclausal relationships: Studies in the production and comprehension of text (pp. 23-48). Mahwah, NJ: Lawrence Erlbaum.

Sodré, M., \& Ferrari, M. H. (1986). Técnica de reportagem: notas sobre a narrativa jornalística. São Paulo, SP: Summus.

Spinillo, A. G. (1991). O efeito da representação pictográfica na produção de narrativas. Psicologia: Teoria e Pesquisa, 7, 311-326.

Spinillo, A. G. (1993). Era uma vez... e foram felizes para sempre. Temas em Psicologia. Desenvolvimento cognitivo: linguagem e aprendizagem, 1, 67-87.

Spinillo, A. G. (2001). A produção de histórias por crianças: a textualidade em foco. In A. G. Spinillo, J. Correa \& S. Leitão (Orgs.), Desenvolvimento da linguagem: escrita e textualidade (pp. 75-111). Rio de Janeiro, RJ: Nau.

Spinillo, A. G. (2005). O uso de coesivos por crianças com diferentes níveis de domínio de um esquema narrativo. In M. G. B. B. Dias \& A. G. Spinillo (Orgs.), Tópicos em Psicologia Cognitiva (2a ed., pp. 83-116). Recife: Editora Universitária da UFPE.

Spinillo, A. G. (2009). A consciência metatextual. In M. Mota (Org.), Desenvolvimento metalinguístico: questões contemporâneas (pp. 77-113). São Paulo, SP: Casa do Psicólogo.

Spinillo, A. G., \& Martins, R. A. (1997). Uma análise da produção de histórias coerentes por crianças. Psicologia: Reflexão e Crítica, 10, 219-248.
Spinillo, A. G., \& Oliveira e Silva, A. P. (2010). Coesão e estrutura textual: uma relação investigada a partir da escrita de textos narrativos e argumentativos. In M. J. M. Luna, A. G. Spinillo \& S. G. Rodrigues (Orgs.), Leitura e produção de texto (pp. 101-136). Recife: Editora Universitária.

Spinillo, A. G., \& Pinto, G. (1994). Children's narratives under different conditions: A comparative study. British Journal of Developmental Psychology, 12, 177-193.

Spinillo, A. G., \& Pratt, C. (2005). Sociocultural differences in children's genre knowledge. In T. Kostouli (Ed.), Writing in context(s): Textual practices and learning processes in sociocultural settings (pp. 27-48). New York, NY: Springer.

Spinillo, A. G., \& Simões, P. (2003). O desenvolvimento da consciência metatextual em crianças: questões conceituais, metodológicas e resultados de pesquisas. Psicologia: Reflexão e Crítica, 16(3), 537-546.

Stein, N. L. (1988). The development of children's storytelling skill. In M. B. Franklin \& S. Barten (Eds.), Child language: A book of readings (pp. 228-297). Oxford: Oxford University Press.

Stein, N. L. \& Policastro, M. (1984). The concept of a story: A comparison between children's and teacher's viewpoints. In H. Mandl, N. L. Stein \& T. Trabasso (Eds.), Learning and comprehension of text (pp. 113155). Hillsdale, NJ: Lawrence Erlbaum Associates.

Tannen, D. (1982). Oral and literate strategies in spoken and written narratives. Language, 58, 1-21.

Teberosky, A. (1996). Informative texts of young schoolchildren. In C. Pontecorvo M. Orsolini, B. Burge \& L. B. Resnick (Eds.), Children's early text construction (pp. 259-276). Hillsdale, NJ: Lawrence Earlbaum Associates.

Teberosky, A. (1990). Reescribiendo noticias: una aproximacion a los textos de niños y adultos. Anuário de Psicologia, 47, 43-63.

Teberosky, A. (1992). Reescribiendo textos: producción de adultas poco escolarizadas. Infancia y Aprendizaje, 58, 107-124.

van Dijk, T. A. (1992). Cognição, discurso e interação. São Paulo, SP: Contexto.

van Dijk, T. A. (1995). Estructuras y funciones del discurso. México: Siglo Veintiuno.

van Dijk, T. A. (1997). The study of discourse. In T. A. van Dijk (Ed.), Discourse as structure and process (pp. 1-34). London: Sage.

Vygotsky, L. S. (1991). Pensamento e linguagem. São Paulo, SP: Martins Fontes.

Recebido: $22 / 05 / 2013$

Revisado: $11 / 09 / 2013$

Aceito: 21/11/2013 